\title{
Family Resiliency in a regular education teacher divorcee
}

\begin{abstract}
This research Identifies resilient family factors presented by La Paz teacher who is divorced from a regular education, WHO performs her professional duties in the morning shift and in the afternoon shift in two different educational establishments, Besides managing to distribute her time with her children, Their Personal life and the restructuring of the family after divorce, for th purpose the research use qualitative thematic analysis from the in-depth interview That Facilitates the elaboration of the results denote the resilient That family factors emerge from them to That from the crisis.
\end{abstract}

Volume 9 Issue 4 - 2018

Oliver Rolando Peñafiel Muñoz

Department of Psychology, Bolivian Catholic University, Bolivia

Correspondence: Rolando Oliver Peñafiel Muñoz,

Department of Psychology, Bolivian Catholic University, Bolivia, Email olicho@hotmail.com

Received: May 01, 2016 | Published: July 17, 2018

Keywords: resilience, work, divorce

\section{Introduction}

Within the historical foundations of resilience is the first article published by Scoville in 1942 where he uses the term to refer to dangerous situations that affect children, but if the family rootlessness, subsequently acquiring the definition of the field of physics to bring to the field of psychology was built by John Bowlby (1958) in the late 70's defining it as a moral support, quality of a person who is not discouraged and leaves abate. ${ }^{1}$ In the decade of the 80 's and 90 the first longitudinal studies were performed by Werner in 1982, Werner and Smith in 1992, Gramezy, Masten and Tellegen in 1984, 1992 and Benson Gamezy in 1997 where it was understood to resilience as a dynamic process among factors (Luthard, 2000). In 1991 the first seminar on resilience in Lesotho, Southern Africa organized by the Foundation Bernard Van (Klinikert Gate, 2002) is performed. 1992 Loosel presents the results of their research on resilience to the general assembly of BICE in Geneva, adding resilience to some application programs, the first time the concept was applied as guiding work outside the Anglo-Saxon world ${ }^{2}$ from research into practice (Puig and Rubio, op.cit). Thus understands resilience as the ability to succeed in socially acceptable way, despite stress or adversity, typically they involve a serious risk of negative outcomes ${ }^{2}$ and the ability of human beings to cope with life's adversities, overcome and even be transformed by them. ${ }^{3}$ Family-labor ratio depends primarily on the cultural pattern that determines in different societies the role played by family members according to their sex and age. This ranges from options in which both spouses are suppliers, passing patterns of division of labor between men and women both are caregivers and suppliers, to the more traditional model, women who remain in the field of domestic reproduction, while male household members participate as providers of paid work. ${ }^{4}$ To spread less authoritarian relationships between spouses and these with their children, while necessarily lowers the "burden" of housework, and is more time available for the spouse carries out activities outside the home, the above linked to rising social services and expanding the horizons of consumption, has encouraged couples that increasingly seek to generate a second income at home. With the aim of maintaining access to health, education and housing, and in order to achieve better standards of consumption, increasingly available in open economies (Schkolnik, op.cit). The teaching profession is profoundly affected by scientific and technological, economic, social and cultural changes occurring in today's society, ${ }^{5}$ the teacher is faced with increasing and conflicting demands, since it must be transmitter and time critic of culture to new generations. You are asked to integrate the learner as socially committed and responsible member in a society that is constantly economic and social crisis. In addition, it must be constantly updated, all this carries a high risk of occupational stress that can have health consequences. Teaching has been considered a particularly stressful occupation. ${ }^{6}$ Day $^{7}$ notes that the resilient teachers exert an obvious moral and ethical responsibility, is essential to induce the development of students' abilities to act on behalf of all teachers in higher education institutions foster capacity ratio coworkers, assigning responsibilities to engage them as part of organizational identity. With behavior contrary, teachers are mostly characterized by introspection, initiative, humor and creativity, opposing designated by Campo (2000), who believes that these traits are needed in the resilient person. ${ }^{8}$ Delage $^{9}$ raises the family resilience as the capacity developed into a family deeply shaken by a crisis, to support and help one or more of its members, direct victims of difficult circumstances or build a rich and full realization of life for everyone of its members despite the adverse situation that has undergone the set. Family resilience has been defined as positive behavioral patterns and functional competencies "family" unit shows under stress or adverse circumstances, determining its ability to recover maintaining its integrity as a unit, while ensuring and restores the welfare of each member the family and the family as a whole. ${ }^{10}$ The roots of these definitions of family resilience can be found in the theory of Family Development, which was formed from research on family trajectories of coping with stress ${ }^{11}$ developed in the 1950s by Hill in the ABC model - X. In this model, three subsequent stages are identified to a family crisis:

1. period of disorganization: incremental characterized by conflict, finding ways of coping and an atmosphere of confusion, anger and resentment.

2. A recovery period: during which new means to meet the crisis are discovered.

3. A period of reorganization: where a family is reconstructed to or above the previous operation to the crisis. 
In this line, one of the major theoretical developments on family resilience comes from work McCubbin, Patterson et al, who have explored in a series of studies the behavior of families coping with stress in the ABC-X Double model, ${ }^{10-13}$ developing a model family resilience called family response adjustment and adaptation (family adjustment and adaptation Response - FAAR model ). This model of family resilience is built on five theoretical assumptions: families experience stress and hardship as a predictable aspect of family life throughout the life cycle; own strengths and develop skills to protect and assist its members in recovery; They benefit and contribute to a network of relationships in the community, particularly during periods of stress and family crisis; They seek, negotiate and establish a common vision that will give them meaning, purpose and a shared perspective to move forward as a group; and families confronted with significant crises stress and seek to restore order, balance and harmony even in the midst of a period of great upheaval. ${ }^{10}$ FAAR model in the active processes in which families are involved in balancing family demands with family skills are emphasized. Simultaneously, this balance between demands and capabilities of the family, interacts with family meanings, to reach an appropriate level of adjustment or adaptation family. ${ }^{14-16}$ Resilient families are able to build a shared belief system that orients toward recovery and growth. This first process of family resilience becomes possible to normalize and contextualize adversity and stress, creating a sense of coherence that redefines the crisis as a manageable challenge. This concept has also been called "familiar pattern" in the literature on family resilience. ${ }^{17}$ In families who manage to turn their resilience an evolutionary concept of time and becoming seen as a continuous process of growth and change; In contrast, families are stuck in dysfunctional patterns, especially the multiproblemáticas- lack this sense and symptoms usually appear in times of disruptive transition that freeze and distress. ${ }^{18}$ Hope, the possibility of recovering some internal security, to re-launch the thought processes are the three basic assumptions of resilience, but to fully develop all three need the presence of an attentive atmosphere of support there is always possibility of greater hope among close friends, relatives and even therapists. So when someone manages to share their hope, it becomes even more hopeful, since maintaining a promising future is a dynamic autoaliento. ${ }^{9}$

The ability of family reorganization after the crisis is based on what Walsh ${ }^{19,20}$ calls family connection, but Olson (1989) Kali1 ${ }^{21}$ and others have named family cohesion. It involves mutual support and commitment to collective goals. When trying to stimulate the family connection, old hatreds, the "ghosts of the past" notoriously difficult process, making it necessary to seek reconciliation in damaged relationships, forgiveness, or at least a temporary truce. Part of the process of family reorganization facing a crisis are to incorporate new resources in a coordinated manner. ${ }^{22}$ Now, the search for new sources of support involves the paradoxical risk of opening too the family system to the intervention of third parties who may be involved too, in an uncoordinated manner and insensitive to the family environment, eventually disrupt and dissolve their families processes autonomy and resilience. ${ }^{23}$ This risk should never be underestimated, and any intervention in the question of the relevance, joint actions and dosing plays a central role. Moreover, the processes of family resilience are based on communication skills and problem solving. This variable has been worked by family therapists, ${ }^{17}$ who have agreed it should be clear, encouraging open emotional expression and collaborative search for solutions. ${ }^{24,25}$ It also requires that family members can share a wide range of emotions such as joy and pain, hopes and fears, successes and frustrations. ${ }^{21-24}$

In order to bring the family resilience it is required that the family maintains a positive outlook, but realistic situation, dominating as possible and accepting the inevitable. In this process plays an important role transcendence and spirituality, aspects that until recently were considered alien to scientific research. The impulse to transcend inspired to envision new possibilities, finding faith often the engine for growth after the crisis hit. ${ }^{26}$ In Bolivia in 2003, almost 7\% of women of childbearing age have dissolved their conjugal union, solutions present from an early age, between 20 and 24 years and there is $6 \%$ of separated women over forty years $11 \%$ of women are divorced or separated, $4 \%$ of men are divorced and separated $0.6 \%{ }^{27}$ According to family judges up to $30 \%$ have increased cases of divorce, some are due to migration, as well as the difficulties of life in common and sociocultural difficulties, it is not insignificant that $30 \%$ argumente abuse as the main reason to dissolve the bond with partner estimated family judges in the Family Guidance Service. ${ }^{28}$ Qualitative research has shown specific processes of family resilience as the addressed context, but also transverse processes. Highlighting three types of studies: psychosocial adversity and positive parenting, family displacement by armed violence, disease and cancer in a child. The processes were repeated: perseverance in objectives and activities that benefited the family unit; the support or mutual support by an empathetic attitude other; and actively seeking new support networks. ${ }^{26}$

In the case study on psychosocial adversity and positive parenting by Silva et al. ${ }^{29}$ in 2009 they highlighted the specific processes of parental sensitivity, meeting the needs of their children, creating a relational space potential of children. In addition, quantitative studies reaffirm the distinction between context-specific processes, versus transverse processes, most notably the latter: to create spaces and communication processes in the family; jointly solve problems; strengthen family cohesion and mutual support; enrich the quality of the parent-child interaction; practice and develop parenting skills; and access to sources of social support..$^{30}$ Rodrigo et al., ${ }^{31}$ worked with 418 families in psychosocial risk where he found that resilience is not determined by evolutionary or structural factors, but depends on the opportunities development contexts and which is key to encourage the development of parenting skills. Moreover, Johnson ${ }^{32}$ working with 180 families with a psychiatric hospitalization denoting the level of family functioning and family sense of competition. Orthner et al., ${ }^{33}$ in his study of families with low income in a population of 373 families found that family communication, problem solving and access to social support are relevant. Greeff \& Van der Walt ${ }^{34}$ meanwhile studied 34 families with an autistic child recognizing the important topics on patterns of open and predictable communication, flexible family supportive environment, committed and familiar "strength" strategies internal coping and external, social support, socioeconomic status, a positive outlook on life and family belief system.

\section{Method}

This research focuses on the case study, concurring in a verbal representation of a situation of reality that places the reader in the role of participant in the situation, it requires that the case be worded in such a way that simulates reality, obtaining reliable conclusions. ${ }^{35}$ The case investigated was performed with a paceña divorced 49 -year-old 
mother of two boys of 25 and 23 years old, currently it performs its duties as a teacher of initial level for 22 years in two establishments, the tomorrow at a private school and evening at a state school, weekends making higher education. The interview was aimed at understanding family functioning resilient she has for her two sons in relation to their work activities and the development of their divorce, the technique used in this study was the in-depth interview, which characterized by asking a question from her base and secondary questions emerge that develop in obtaining all the information, using this case a central question focused on thought. The analysis used is called thematic as it is a method to identify, organize, analyze in detail and provide patterns or themes from a careful reading and re-reading of the information collected and thus infer results conducive to the proper understanding / interpretation of the phenomenon study. ${ }^{36}$

In addition, the thematic analysis provides an exhaustive process to identify numerous cross references between emerging issues and all information, allowing to link various concepts and opinions of participants and compare them with data that have been stored in different situations during the investigation. ${ }^{37}$ The analysis of the responses by the participant from methodological epistemological for thematic analysis framework is phenomenology, which is a comprehensive and interpretive theory of social action that explores the subjective experience in the world of everyday life people. From this perspective, it is considered that people living in the world of everyday life are able to attribute meaning to a situation; therefore is the subjective meaning of experience which is the subject of study. ${ }^{38}$ Thematic coding is applied as a multi-step procedure, again in terms of comparability analysis. So it produces a brief description of each case, which is again checked continuously and modified if necessary for subsequent interpretation. This description of the case includes a claim that is typical for the interview, a brief description of the person with respect to the research question, so that the thematic analysis can identify the essence of a phenomenon, transforming the experience in a textual expression of its essence. ${ }^{39}$

\section{Results}

Then, the categories used in the investigation are shown, which are sequentially distributed for proper analysis.

\section{Counterweight everyday}

It is understood from the appearance of a context biopsicosocial high risk, balanced by active protective processes, ie a family resilience by daily counterweight would be, for example; a family living in a poor neighborhood with high levels of violence and microtráfico, but manages to keep prosocial values, flexible family roles and shared routines, counterbalancing the potentially harmful environmental influences. ${ }^{26}$

The difficulties disorganising unbalance the family system appear, the presence of internal dynamics and strategies that reorganize providing control over each of them, remain that way as the participant raises the following paragraph is necessary.

"Well, I worked all day, in the morning in my public high school, leaving home at eight o'clock and arriving at noon to get back out to work at two in the afternoon and get home at six and a half or so. " "Look, I got up at six in the morning to leave cooked and then we get ready and do my activities"
Recognizing as participant describes how it has to organize among their housework and work activities to give their children a space of safety and security which then translates into collective responsibilities among the three.

"Yes, but it was difficult to generate them habits, as everyone was with his things and sometimes behaved stubborn, but we always resorted to speak to achieve handling problems and so everyone feel better"

The ability to solve the problems through dialogue allows them an optimal resolution of the difficulties and emotions of each are respected and dialogue as a strategy then the solution is allowed.

"Now, after so many years, all handled very well, of course, I do not get up so early, everyone helps me with household duties, then I feel calmer, they already know how to handle well, we all do functions in the house, for example, of all that I possess, distribute it on needs and then each has its amount for the month, then if the phone used to call cell already know they should write down payment due to them for the call time. And so with the rest of the activities, I admit even less clothing, weekends I wash their clothes, is what still spoiled them "

Important to recognize that the implementation of limits, rules and determined in each of the family members functions, as they develop so dissimilar forms of coexistence that allow restructuring and coordination of elements needs of crisis.

"At the beginning it was difficult, because when I separated, my mom got much to discredit me, and that cost me a lot, make me respect and my children obey me, and that among the three we can move forward. After that, things changed and the rules worked best in the house, and everyone took care of what he played and also guys who are very respectful to me. "

"I recognize that at the beginning was awkward, and that things had to do as I said and the boys behaved stubborn, but then my mom sometimes helped us a lot, because for hours going home to see if the boys They fulfilled what they did, and then I put good hard, and told them to do and they then did "

"Yes, usually in the room, it is where we met the three and each does its activities, and also took the opportunity to talk."

In the process of building family resilience implementing rules and hierarchies of the same core allow proper operation of each of its members, of course temporary interference of any member outside the initial system you can stabilize until other ownership their role in the family.

"Now we all know what to do and how to do, go to college and each with their activities, they also have common activities, and me with my work and now if I go out with my friends, everything works fine, since no one meddle in each other's lives, if they make it right there because disturbing them and the same with me, respect my decisions and share everything very well. "

After the family members become accustomed to operate on the basis of the functional rules that are allocated between them, during the life cycle each will assume its role and responsibility for self and family members, respecting and validating each.

"How ally?, Is to say if putting aside of one of them by his other son feel bad?, no, try to be very fair, both wore chirlazo even if one is 
to blame, I have always believed if anything they are both those who do, rather they covered things, so it was difficult to separate them out something had to be there together and just talked all three. " "No, it's like the answer I said a moment ago, we are all equal and have equal rights, of course they know that if someone needs something before the other, then a sacrifice is made and then it is completed to others depending on what is needed. "

The grant relevance to the phratry favors the development of the family, as no allies or relational triangles are generated, on the contrary, the behavior is corrected in terms of both, giving them the chance to feel each with the same privileges and restrictions that mom can give them. So that the time allotted between the order of his family and the fulfillment of their work activities places it in a privileged place in the family as it is distributed without rob it to space each.

Relational ties that bind people and systems allow them to move towards a shared path, finding the basis of the most critical processes for human development: for example, in biological and psychological stress processes, self-regulation, conformation cerebral citoarquitectura and operation, ${ }^{40}$ in building operating models or schemes that organize experience and give it meaning, ${ }^{42}$ dynamic stability conferring mental health ${ }^{41}$ and the conquest of the essential conditions for development biopsicosociales ${ }^{43}$ among many others. In all, relational experiences play an undeniable role ${ }^{44}$ (Figure 1).

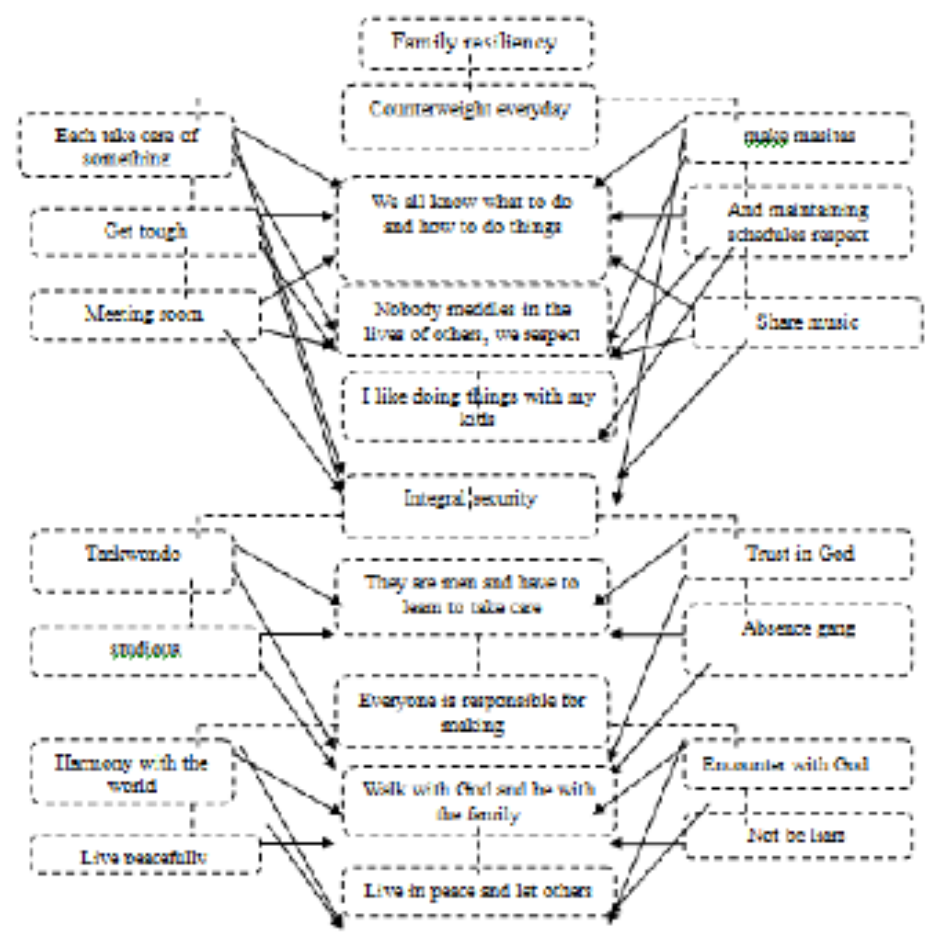

Figure I Tree cognemas: family resilience from everyday counterweight.

\section{Recovery}

A crisis in which the risk factors, vulnerability and stress (Eg unemployment, parental depression and alcoholism, among others) outweigh family resources, generating a sharp deterioration in the family (eg, dynamics of child abuse.); after which relational processes of improvement are activated (eg., family converses your problem is most likely in the early stages of the process) or requires the intervention of third parties (eg., enters a family intervention program in stages over it advanced deterioration) is understood as a family resilience by recovery. ${ }^{26}$

"Yes, everything you do is so then they are better people and do better in life, I think that's what a like mom wants, plus I am very proud of my children, Carlos is rock musician and also graduated the following week of social communication, has many achievements and also it is very good as a person, has many friends who love him and Mario is very applied in his career and also that like his brother does to music they with other boys have their rock group, seems to me great !!. If, when you have presentations I'm there because I too like the music they make, have a good time, we travel together, I like doing things with my kids. "

The link allowed by the mother to her children in relation to their tastes and everyday pleasures allow adequate recovery of the family after some adversity, so that part of their pleasurable activities reinforces the timeshare and subsequent autonomy they have on the decisions they make in what they do taking responsibility for their subsequent actions.

"You You mean like everyone behaved, well, Carlos is the greatest, but he never got to tell his brother how to do things, he is very respectful of all, however Mario, the if placed in the position saying to do or how to act when it matured was changing, there is more respect between the two, because everyone respects the other and at the same time take care, I think the more protective there is Mario, Carlos is protective when things are difficult. And I always mom, and they do not exceed my authority, but also do not see me as a military. For example, everyone already knew they had to do, so they had to do, and I cleaned everything else, living room, kitchen, bathroom, when came 
the friends of the boys, they knew they had to clean up, fix before and after, it was his responsibility. "

The emergence of rules distributed in each and given the collective support in difficult times allows members to recover, as the mother no longer the authority, but also becomes an unattainable figure of power.

You mean they do not hurt?, so, first spoke them to watch out on the street, at school, who do not accept drugs and gangs, as these people are dangerous, then I decided to get them to Tae Kwon Do to learn to defend themselves, they are men and have to learn to care, but things never stopped him them for fear, I trust in God and my kids do the right thing.

The use of martial arts and protective link received by his belief in God, the transmission of values to their children, allow the mother feel confident that they will do the right thing when she has to be temporarily absent.

"Values are needed, teach them to respect people in general it is something I always told them, who are loyal and good companions, we met for tea when baked and there took advantage to talk and pass on good values, now his school it was a place transmitting them good values, his grandfather who is a Jehovah's Witness was there speaking of the Bible, order and good treatment while being themselves is something we were taught. "

The presence of familiar command transmitted from the mother to the children's presence grandfather sustaining belief in the Bible become protective factors that allow them to bases where they can sustain without causing harm or damage.

"You mean what they learned with their friends or school, if, as I told the school were taught good values, and what they learned with their friends I assessed and whether it was a good thing we talked about or if not then we met to speak, but the time of tea, we always helped because we could interact and although there sometimes felt annoyed, was good reason together ".

"Now, they are based on being in harmony with the world beyond God, is at peace with the world, live in peace, as my kids say, without the ego, because the ego makes people distance themselves, then it is not lying to us do not like liars, they say something and act otherwise, be in harmony with the world is to live in peace and let others live ".

The familiar ability to stimulate critical thinking from the teachings they receive in school, messages at home, become a proximal protective factor because they have the ability to question social beliefs and allow appropriating functional beliefs for them and relational links. Therefore the resilience approach "minimum", the role of adaptation, ie resilience would be a dynamic process of positive changes within a context of significant adversity. ${ }^{45,46}$ Moreover, resilience approach "maximum" is not limited to the recovery or continuation of the previous equilibrium after the crisis, but commitment to transformation and growth. In this view resilience is the human capacity to face (Figure 2).

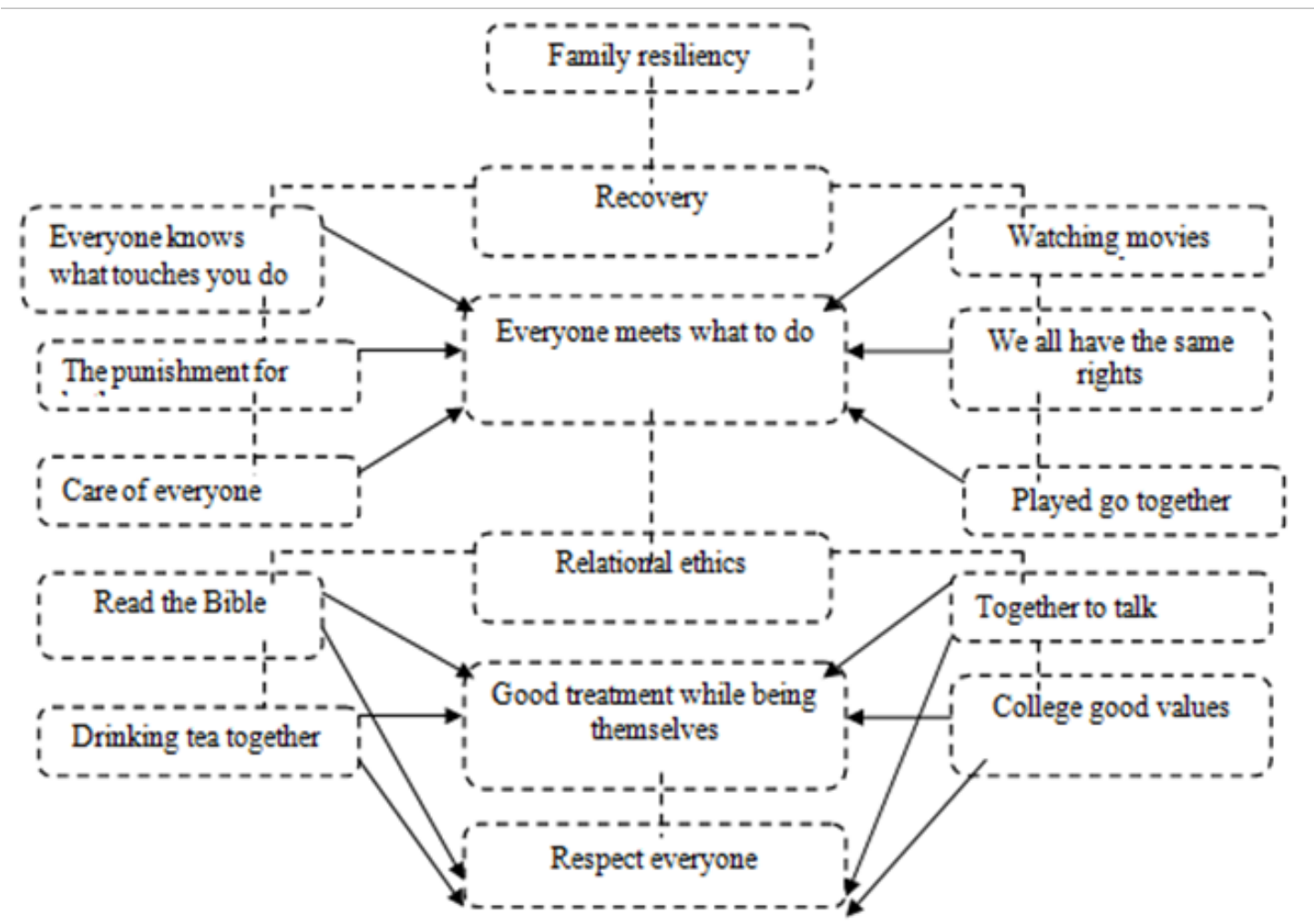

Figure 2 Tree cognemas: family resilience from recovery. 


\section{Increase}

This topic identifies an event with high demands and stress (eg., A diagnosis of serious illness, divorce, employment), but a process of extended family deterioration is generated, promptly activated accumulated by the family equity (eg., shared for years) spirituality or mobilization of external resources (eg., immediate professional support), generating a performance even higher, ie, a family resilience for growth. ${ }^{26}$

Growth from spirituality and hope are placed as a fundamental category within the intersubjective development of each person to his family, work and relational system as a whole. Since in the process of overcoming the crisis it has a something or someone to turn to in the absence of other parallel protective categories, allowing you the ability to face adversity with dissimilar strategies emerging from the protective shelter and promoter that sends him to continue. It is from this as any belief supported by the transcendence of the person from protective shelter which undergoes allows you to increase the recurring crisis with hope and strength.

In the case analyzed the participant concerns in relation to growth the following:

"It was very difficult at first, because I'd get angry and I crashed with the guys, it helped me to go to church that has always done me good, I am reassured and know that everything will happen, well I smoked a cigarette and I started to think about what becoming and I planned because I know that when you live without disturbing anyone all energies are aligned so that you're better "

Denoting the transcript submitted in advance, the participant described the belief that emphasis has directed towards growth and hope, which exists beyond the temporary action to which it is subjected. Since each of the behaviors allow the opening to optimal and free transcendence sequentially difficulties.

"Umm, if you also put me to wash clothes, but I did not like, but it could think until things are given good, but bake pastries that if I changed because there you know there is hope because what you believe and give back so you that I do not hurt anybody and I try to live happily. I am not a staunch Catholic, but I always believed in God and the Virgin, and also knew that some things happen and you have to go forward "
The approach to which it refers expression allows us to recognize the growing projection that presents the participant, giving his divine belief and temporal tranquility, it is then that difficulties do not become an impediment rather behave as drivers of a tour continued to ever higher and achievable goals.

"It is still complicated, but see how the guys come out ahead, and that everything done is not in vain, I have conveyed strength, love of literature, poetry, music, they get angry and are passed and they can do things to feel better, now I feel much better as I go out with my friends and that I really like, I mean, I get distracted, as I said, is different, I think things happen for a reason and that life is very short, so you have to enjoy it to the fullest and make the difficult moments do not follow there, follow ".

As shown in paragraph expressed by the participant, growth is part of their beliefs, not to be sinking, overcome adversity with actions that determine their recovery, granted freedom from poetry, music and literature. Each of them allows the approach to different opportunities in life narrated grow and spread without fear and with much strength. Openness to be with friends in the tranquility distracted denoted, confident that the children will work out well because it was working on the family from the strength and displayed beyond the difficulty.

"I take it in stride and good sense of humor, I try to be quiet and that transmit the guys, and so we try to handle problems"

The ability to see the difficulties exquisite sense of humor allows different perception of the problem, giving relevance to the solution and decreasing the intensity of difficulty.

In the paragraphs above we can see that the family works directed towards the growth of each of the members and relational life in general, it is shown that there may be anger at times, but then the ability to handle adversity with a sense the humor, hope, and desire to transcend past the difficulty.

Both individually and as a family the resilience concept from growth is seen as a force that opposes the potential devastation of adversity: it is not possible to speak of resilience in the absence of adverse conditions with high probability of generating negative results in a person or group. ${ }^{46,47}$ Adversity is then the germ of resilience, pain is the seed of overcoming obstacles and are the incentive to sustained effort toward a goal that characterizes people and resilient families ${ }^{48}$ (Figure 3).

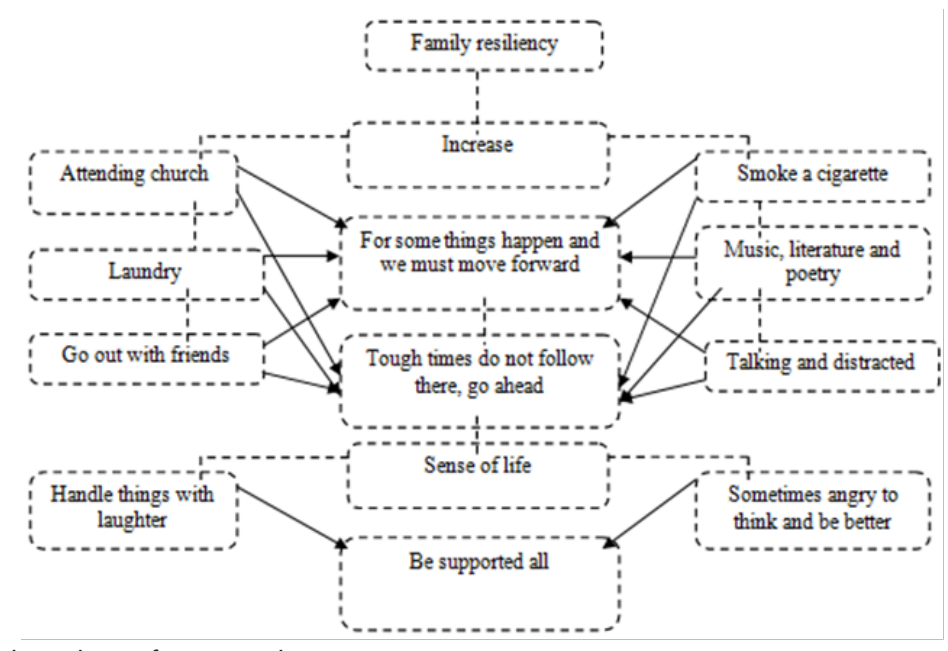

Figure 3 Tree cognemas: family resilience from growth. 


\section{Conclusion}

The notion of resilience, individual resilience is rooted in the study of developmental psychopathology versus the successful development, ${ }^{45}$ while family resilience is anchored in studies of family therapy and coping with family stress, ${ }^{23}$ showing a high heuristic potential for theoretical articulation in clinical and psychosocial intervention with highly vulnerable families ${ }^{49,50}$ and the enrichment of new models of health care family. ${ }^{51}$ Resilient factors found in the participant show that family and work interaction, each of which are essential for optimal functional outcome familiar. Resilience, whether seen in people or families, is not a static quality, a trait or immutable characteristic, but is a dynamic and changing process that manifests against certain demands, while it can not be seen in other conditions or times. ${ }^{52}$ Regardless of whether individual or family, resilience is always contextual and historical. Although this procedural component of resilience has been constantly emphasized, ${ }^{45-53}$ continues to apply in practice a search of that "intrinsic quality" to the person who explains his extraordinary results under stress.

The participant denotes the presence of beliefs that allow the emergence of individual and family hope, since at no time shown despondent and interaction between their work and family is harmonious, which adversities lack all meaning and allow the appearance that something good will emerge. In this sub category control the situation can identify the participant claims to have optimal control of the situation in reference to his family and his work, as the time spent is meager for their work activities, however, the behaviors described give for good interaction between family and work promoting family relationships. Family function represents an optimal family interaction, as each member has its own roles and functions which promote proper family functioning, is therefore that, although the very limited progenitor time, family functioning is suitable and harmonic evolutionarily. Each of the resilient factors found recognizes the participant as a functional between the family and the teaching work, because at all times exiguous time having their work activity ceases to be relevant within the family benefit, since the presence of resilient factors who protect and promote the family relational outcome. Transmission of family mythopoiesis strengthens the interaction between its members and that this way even in the temporary absence of the parent, beliefs taught in the family recognized actions intensify their growth from adversity.

\section{Acknowledgements}

None.

\section{Conflict of interest}

The author declares that there is no conflict of interest.

\section{References}

1. Puig G, Rubio J. Handbook of Applied resilience. Gedisa: Barcelona; 2011.

2. Vanistendael S. The résilience ou le réalisme of L'Esperance: blessé mais pas vaincu. Geneva, Bureau International Catholique de l'enfance; 1996.

3. Grotberg E. Resilience in the world today. How to overcome adversity. Gedisa: Barcelona; 2006.

4. Schkolnik M. Tension between family and work. Cepal. Chile. UNFPA. 2004.
5. García E. Stress, teaching profession and personality of the teacher. Anxiety and stress. 1996;2:245-260.

6. Matud Aznar M. Work stress and health teachers: a differential analysis by gender and type of education. International Journal of Clinical and Health Psychology. 2002;2(3):451-465.

7. Day. Passion for teaching. Personal and professional identity of teachers and their values. Nacea - Madrid, Spain; 2006.

8. Fontaines T, Urdanteta G. Ability resilient teachers in university settings. 2009;10(1):163-180.

9. Delage M. The family resilience. Gedisa: Barcelona; 2010.

10. McCubbin M, Balling K, Possin P, et al. Family resilience in childhood cancer. Family Relations. 2002;51(2):103-111.

11. Gracia E, Musitu G. Social psychology of the family. Barcelona: Paidós; 2000.

12. McCubbin H, Patterson J. The family stress process: The double ABCX model of family adjustment and adaptation. Marriage and Family Review. 1983;6(1-2):7-37.

13. McCubbin H, McCubbin M. Typologies of resilient families: emerging roles of social class and ethnicity. Family Relations. 1988;37(3):247-254.

14. Patterson J. Families experiencing stress: The family adjustment and adaptation response model. Family Medicine Systems. 1988;6(2):202-237.

15. Patterson J. Integrating family resilience and family stress theory. Journal of Marriage and Family. 2000a;64(2):349-360.

16. Patterson J. Understanding family resilience. $J$ Clin Psychol. 2002b;58(3):233-246.

17. Hawley D. Clinical Implications of family resilience.The American Journal of Family Therapy. 2008;28(2):101-116.

18. Coletti M, Linares J. Systemic intervention in social services to the family multiproblem: Ciutat Vella experience. Barcelona: Paidós Family Therapy; 1997.

19. Walsh F. Family Resilience: A framework for clinical practice. Family Process. 2003;42(1):1-18.

20. Walsh F. Family Resiliency. Amorrortu: Madrid; 2004.

21. Kalil A. Family resilience and good child outcomes: A review of the literature. Center for Social Research and Evaluation. Ministry of Social Development: New Zealand; 2003.

22. Landau J. Enhancing Resilience: Families and communities as agents for change. Fam Process. 2007;46(3):351-365.

23. Colapinto J. Dilution of family process in social services: Implications for treatment of neglectful families. Fam Process. 1995;34(1):59-74.

24. Minuchin S, Fishman, HC. Family Therapy techniques. Buenos Aires: Paidós Family Therapy; 2004.

25. Góngora Navarro J, Beyebach M. Advances in Systemic Family Therapy. Buenos Aires: Paidós Family Therapy; 1995.

26. Gomez E, Kotliarenco M. Family Resilience: a research and intervention Approach with multiproblem families. Journal of Psychology. 2010;19(2).

27. National Statistics Institute. National Demographic and Health Survey. Bolivia: ORC Macro/Measure. 2004.

28. Family Counseling Service. divorce rate in Bolivia. Archbishopric La Paz; 2008.

29. Silva M, Lacharite C, Silva P. Processos that sustentam to family resilience: estudo um case. Text \& Context Nursing. 2009;18(1):92-99. 
30. Benzies K, Mychasiuk R. Fostering family Resiliency: A review of the key protective factors. Child \& Family Social Work. 2008;14(1):103-114.

31. Rodrigo MJ, Camacho J, Máiquez ML, et al. Factors influencing the prognosis of recovery in psychosocial risk families: the role of the resilience of the child. Psicothema. 2009;21(1):90-96.

32. Johnson E. The effect of Family Functioning and family sense of competence on People with Mental Illness. Family Relations. 1998;47(4):443-451.

33. Orthner D, Jones-Sanpei H, Williamson S. The resilience and strengths of low-income families. Family Relations. 2004;53(2):159-167.

34. Greeff A, Van der Walt KJ. Resilience in Families With an autistic child. Education and Training in Autism and Developmental Disabilities. 2010;45(3):347-355.

35. Ellet W. The case study handbook. Harvard Business. Massachusetts, 2007.

36. Braun V, Clarke V. Using thematic analysis in psychology. Qualitative research in psychology. 2006;3(2):77-101.

37. Alhojailan M. Identification of learners attitudes Regarding the implementation of read/write web: a case study in higher education. Center for Higher Education. 2012;58-73.

38. Honeys M, Tonon G, Alvarado S. Qualitative research: The tematic analysis for the treatment of information from the approach of the social phenomenology. Univ Humanist. 2012;74:195-225.

39. Gonzales, Cano. Introduction to data analysis in qualitative research: concept and characteristics (I) in Nure Research. 2010;44.

40. Shore A. The effects of early relational trauma on right brain development, regulation and Affect Infant Mental Health. Infant Mental Health Journal. 2001;22(1-2):201-269.

41. Lecannelier F. Attachment and Intersubjectivity. Part Two: attachment theory. LO M Editions: Santiago de Chile. 2009.
42. Fonagy P, Target M. Attachment and reflective function: Their role in selforganization. Dev Psychopathol. 1997;9(4):679-700.

43. Walker S, Wachs T, Gardner J, et al. Child Development: Risk factors for adverse outcomes in developing countries. Lancet. 2007;369(9556):145-157.

44. Shonkoff J, Phillips D. From Neurons to Neighborhoods: The Science of Early Childhood Development. Washington DC: National Academy Press. 2000.

45. Luthar S, Cicchetti D, Becker B. The construct of resilience: A critical evaluation and guidelines for future work. Child Development. 2000;71(3):543-562.

46. Rutter M. Resilience, competence and coping. Child Abuse and Negl. 2007;31(3):205-209.

47. Masten A, Obradovic J. Competence and resilience in development. Ann N Y Acad Sci. 2006;1094(1):13-27.

48. Cyrulnik B. The murmur of ghosts. Gedisa: Barcelona; 2003.

49. Gomez E, Muñoz M, Do AM. Multiproblem and social risk families: characteristics and intervention. Psyche. 2007;16(2):43-54.

50. Sousa L. Strengthening vulnerable families. New York: Nova Science Publishers; 2008.

51. Schade N, GonzalezA, Beyebach M, et al. Somatoform disorders in primary care: psychosocial characteristics and outcomes of a proposed family counseling. Chilean Journal of Neuropsychiatry. 2010;48(1):20-28.

52. Kalawski JP, Haz A. Where is the resilience?, A conceptual reflection. Interamerican Journal of Psychology. 2003;37(2):365-372.

53. De Haan L, Hawley D, Deal J. Operationalizing family resilience: A methodological strategy. The American Journal of Family Therapy. 2002;30(4):275-291. 